\title{
Hepatotoxicity: a major complication with critical treatment
}

\begin{abstract}
Hepatotoxicity in one of the major parameters need to be consider in drug therapy, behind the reason that drugs given either in single or in combination for a prolonged period causes liver damage. Most of drug withdraw from the market or pending for approval due to causing hepatotoxicity (Leflunomide, Flutamide, Disulphiram, and Triglitazone) and may be chance to criticize the use based on this toxicity. Hepatoprotective agent opposes this effect while the agent who generates called hepatotoxins. There is no plant in this Universe which is non-medicinal and which cannot be made of use for many purposes and by many modes. This definition rightly suggests that in principle all plants have a potential medicinal value. Medicinal plants have been considered as important therapeutic aid for alleviating ailment of humankind. The present review is aimed at compiling data on promising Phytochemical from medicinal plants that have been tested in hepatotoxicity models using modern scientific system and mechanisms of free radicals toxicity with scavenger which revealed their toxicity belongs to synthetic or herbal product.
\end{abstract}

Keywords: liver diseases, herbal treatment, free radicals, cyp450
Volume I Issue 3 - 2015

\section{Sharma Mukesh K, Sharma Ganesh N,} Vashishtha Vishal, Bairwa Ranjan

School of Pharmaceutical Sciences, Jaipur National University, India

Correspondence: Sharma Mukesh K, School of Pharmaceutical Sciences, Jaipur National University, India, Tel 8094I06545, Email mukeshkumarsharma025@gmail.com

Received: August 01, 2014 | Published: September 08, 2015
Abbreviations: SGOT/AST, serum glutamate oxaloacetate transaminase; SGPT/ALT, serum glutamate pyruvate transaminase; MDA, malondialdehyde; NP-SH, non-protein sulfhydryls; ROS, reactive oxygen species; $\mathrm{H}_{2} \mathrm{O}_{2}$, hydrogen peroxide; $\mathrm{HO}^{*}$, hydroxyl radical; RNS, reactive nitrogen species; 'NO, nitric oxide; $\mathrm{PBN}$, alpha phenyl t-butyl nitrone; CAR, constitutive androstane receptor; RXR, retinoid-x-receptor; rGSTA1/A2, glutathione s-transferase a1/a2; PPAR, peroxisome proliferator-activated receptors; CPT 1, carnitine palmitoyl transferase-1; FAO, fatty acid oxidation

\section{Introduction}

The liver is most sensitive target of xenobiotic due to its working processes such as metabolism and detoxification. Liver toxicity is a leading cause of morbidity and mortality throughout the world and increases day by day. Nearly 20,000 deaths and 2,50,000 new cases observed each year. ${ }^{1,2}$ Liver damage or failure is always associated with hepatocytes necrosis and elevated levels of biochemical parameters like serum glutamate oxaloacetate transaminase(SGOT/AST) and serum glutamate pyruvate transaminase (SGPT/ALT), triglycerides and malondialdehyde (MDA), non-protein Sulfhydryls (NP-SH), bilirubin and alkaline phosphatise. ${ }^{3,4}$ The agents responsible for hepatic trouble may be parasitic and viral infections, autoimmune diseases, genetic predisposition and intoxication with various xenobiotics such as chlorinated solvents, alcohol, alphatoxin, drugs, herbal medicines, food toxins, peroxidized oils, fungal toxins, industrial pollutants and radioactive isotopes. ${ }^{5}$ Most of the hepato toxic chemicals damage liver cell mainly by including lipid peroxidation, DNA damage, depletion of Sulfhydryls, altered calcium homeostasis or mitochondrial permeability transition (MPT) ${ }^{6,7}$ and other oxidative damages in liver. Most of drug withdraw from the market due to drug-induced liver injury (DILI) ${ }^{8}$ or criticize the use of many drugs, including Isoniazid, Labetalol, Trovafloxacin, Tolcapone, and Felbamate. ${ }^{9}$

Although tremendous scientific advancement in modern medicines, hepatic disease remains a global health problem, thus the search for new drugs is still ongoing. Hepato protectives are a class of therapeutic agents that includes synthetic as well as natural product which offer protection to liver from damage or help in regeneration of hepatic cells. Plants are significant source of hepatoprotective drugs. It has been claimed that about 170 phyto constituents isolated from 110 plants belonging to 55 families with different genera do possess hepatoprotective activity which contain a variety of chemical constituents like phenols, coumarins, curcuminoids, lignans, essential oils and terpenoids. Clinical research has also shown that herbals have genuine utility in the treatment of liver diseases. Only a few hepato protectives are evaluated and documented used in local health traditions and pharmacological importance of these plants and their taxonomical relatives can lead to the development of invaluable plant drugs for many dreaded diseases. ${ }^{10}$ The classical systems of medicine such as Ayurveda, Siddha, Unani and Tibetan use about 1,200 plants. Random screening of plants has not proved economically effective. The present review study give evidential explore mechanism of action of medicinal plants against experimentally animal models induced hepatotoxicity and give many links to develop the future trials.

\section{Hepatoprotective}

Hepatoprotective drugs are defined as the drugs which prevent liver diseases. The literature review reveals that a large number of drugs obtained from plant are endowed with hepatoprotective claims either directly or indirectly. Hepatoprotective effects of herbal formulations as well as allopathic are studied against various toxic chemicals like alcohol $\mathrm{CCl}_{4}, \beta$-Galactosamine, Thioacetamide, Paracetamol, Nimusalide, Isoniazid, Rifampicin at different dose with variant time duration which may be in-vitro or in-vivo. Most of toxicity case included oxidative stress (ROS), hydrogen peroxide $\left(\mathrm{H}_{2} \mathrm{O}_{2}\right)$, hydroxyl radical ( $\left.\mathrm{HO}^{\circ}\right)$ and peroxy radicals of biomolecules, depletion of glutathione, low production of ATP and increases permeability of cell membrane. So detoxify of ROS required antioxidant, restoring cofactors and repairing altered biomolecules therapy. ${ }^{11-13}$ In the absence of reliable liver protective drugs in allopathic medical practices, herbs play important role in the management of various liver diseases. These are divided in two categories. 


\section{Synthetic hepatoprotective}

There are no specific allopathic medicines used as hepatoprotective, although different research works are going on some drug like, Ursodeoxycholic acid, S-Adenosyl-L-methionine. Ursodeoxycholic cause decreasing immunoglobulin production by B lymphocytes as well as interleukin-1 and interleukin-2 from $\mathrm{T}$ lymphocytes that produced beneficial effect on plasma membrane ${ }^{14}$ and on mitochondrial oxidation, ${ }^{15}$ and recovery of liver prostaglandin level. ${ }^{16}$ It also upward regulation of glucocorticoid receptor in hepatocytes. ${ }^{17}$ Some authors believe that Penicillamine and polyphenol derivative act as metal chelator, neutralizing the pro-oxidant effect of iron, copper, lead and mercury while amphiregulin serving as anti-apoptotic action by activation of transcription-3 survival pathways, and by upregulated Bcl-xL expression. Silymarin, $S$-adenosyl-L-methione, prostaglandin $\mathrm{E}_{2}$ and polyunsaturated phosphatidyl choline are used as hepatoprotective due to their anti oxidant properties. ${ }^{18,19}$

\section{Herbal hepatoprotective}

The medicinal plants and their derivatives with or without combination have been used as hepatoprotective from several decades, starting with the Ayurvedic treatment, and extending to the
Chinese, European and other systems of traditional medicines. Herbal drugs are recently more popular because of them are in expensive, better cultural acceptability, better compatibility, with the human body and minimal side effects. ${ }^{20}$ The $21^{\text {st }}$ century has shifted towards therapeutic evaluation of herbal products in the trend of the modern concept of evidence based medicinal evaluation, standardization and randomized placebo controlled clinical trials to support clinical efficacy and revealed strengths of the traditional medicinal systems. It is interesting that India is known as "Botanical Garden of the world" due to larger production of medicinal plants, more than 93 plants are used in 40 patented and proprietary multi ingredient plant formulations ${ }^{21}$ which include variety of chemical constituents like polyphenols (ellagic acid, gallic acid, tannins), coumarins, lignans, essential oil, monoterpenes, carotenoids, minerals(zinc, chromium, copper, manganese, iodine, selenium), saponins, glycosides, flavonoids(isoflavones, quercetin, isocatechin), organic acids, enzymes(catalase, glutathione peroxidase), vitamins(A,C,E,K), lipids, alkaloids, xanthenes, curcuminoids, and terpenoids ${ }^{5,22-25}$ that showing antioxidant activities (Table 1). The antioxidants may cure different diseases by protecting the cells from damage caused by free radicals having highly reactive oxygen and nitrogen containing molecules. ${ }^{26-29}$

Table I Plants with Phyto constituents and their screening methods

\begin{tabular}{|c|c|c|c|c|}
\hline Chemical classification & Botanical name & Part used & Screening method & Phytoconstituent \\
\hline \multirow{3}{*}{ Phenols } & Salacia reticulata & Plant & $\mathrm{CCl}_{4}$ & Mangiferin ${ }^{30}$ \\
\hline & Rhodiola sachalinensis & Root & Paracetamol & Salidroside ${ }^{31}$ \\
\hline & Picrorriza kurroa & Root & $\mathrm{CCl}_{4}$ & Picroside- $\left.\right|^{32}$ \\
\hline \multirow{2}{*}{ Flavonoids } & Tecomella undulata & Leaves & $\mathrm{CCl}_{4}$ & betulinic acid ${ }^{33}$ \\
\hline & Uncaria gambir & Heart -wood & $\mathrm{CCl}_{4}$ & Catchin \\
\hline \multirow{4}{*}{ Alkaloids } & Berberis vulgaris & leaves & $\mathrm{CCl}_{4}$ & Berberine $^{34}$ \\
\hline & Fumaria indica & Plant & $\mathrm{CCl}_{4}$ & Protopine $e^{35}$ \\
\hline & Peumus boldus & Plant & $\mathrm{C}_{4} \mathrm{H}_{10} \mathrm{O}_{4}$ & Boldine $^{36}$ \\
\hline & Boerrhavia diffusa & Plant & Ibuprofen & Punarnavine $^{37}$ \\
\hline \multirow{2}{*}{ Xanthines } & Coffea Arabica & Seed & $\mathrm{CCl}_{4}$ & Caffeine \\
\hline & Swertia japonica & Root & D-galactosamine & Tetrahydroswertia-nolin ${ }^{38}$ \\
\hline Monoterpenes & Psoralea corylifolia & Plant & Tacrine & (S)-bakuchio 39 \\
\hline \multirow{2}{*}{ Diterpens } & Andrographis paniculata & Whole- plant & Ethanol & Andrographolide ${ }^{40}$ \\
\hline & Acanthopanax koreanum & Root bark & D-galactosamine & Acanthoic acid ${ }^{41}$ \\
\hline \multirow{3}{*}{ Triterpens } & Glycyrrhiza glabra & Roots & $\mathrm{CCl}_{4}$ & Glycyrrhizin $^{42}$ \\
\hline & Protium heptaphyllum & Trunk & Acetaminophen & $\beta$-Amyrin ${ }^{43}$ \\
\hline & Tetrapanax papyriferum & Leaves & $\mathrm{CCl}_{4}$ & Papyriogenin $\mathrm{A}^{44}$ \\
\hline \multirow{3}{*}{ Coumarins } & Solanum lyratum & Plant & $\mathrm{CCl}_{4}$ & Scopoletin ${ }^{45}$ \\
\hline & Artemisiae capillaris & Plant & D-galactosamine & Esculetin ${ }^{46}$ \\
\hline & Smilax officinalis & Roots & $\mathrm{CCl}_{4}$ & Hesmidesmine $^{47}$ \\
\hline \multirow{3}{*}{ Essential oil } & Anethum graveolens & Fruits & Paracetamol & $\alpha$-phellandrene ${ }^{48}$ \\
\hline & Azadirachta indica & Leaves & Paracetamol & azadirachtin- $\mathrm{A}^{49}$ \\
\hline & Cynara scolymus & Plant & $\mathrm{CCl}_{4}$ & Cynarin ${ }^{50}$ \\
\hline
\end{tabular}




\begin{tabular}{|c|c|c|c|c|}
\hline Chemical classification & Botanical name & Part used & Screening method & Phytoconstituent \\
\hline \multirow{3}{*}{ Lignans } & Silybum marianum & seed & Thio acetamide & Silybin $^{51}$ \\
\hline & Thujopsis dolabrata & Leaves & $\mathrm{CCl}_{4}$ & Desoxypodophyll-otoxin ${ }^{52}$ \\
\hline & Phyllanthus amarus & Leaves & $\mathrm{CCl}_{4}$ & Phyllanthin ${ }^{53}$ \\
\hline \multirow{4}{*}{ Glycosides } & Aloe barbadensis & Leaves & $\mathrm{CCl}_{4}$ & Piceid $^{21}$ \\
\hline & Panax ginseng & Rhizome & $\mathrm{CCl}_{4}$ & Panaxoside A \\
\hline & Polygonum cuspidatum & Roots & $\mathrm{CCl}_{4}$ & Polydatin ${ }^{54}$ \\
\hline & Mallotus japonicus & cortex & $\mathrm{CCl}_{4}$ & Bergenin $^{55}$ \\
\hline Carotenoids & Gardenia florida & Fruits & $\mathrm{CCl}_{4}$ & Crocin $^{56}$ \\
\hline Gallic acid & Terminalia belerica & Fruits & Paracetamol & Trihydroxybenzoic acid ${ }^{57}$ \\
\hline Fumaric acid & Fumaria indica & Whole plant & Paracetamol & Monomethyl fumarate ${ }^{58}$ \\
\hline Aliphatic nitrocompound & Indigofera tinctoria & Aerial parts & $\mathrm{CCl}_{4}$ & Indigtone $\mathrm{e}^{59}$ \\
\hline Tannin & Terminalia catappa & Leaves & $\mathrm{CCl}_{4}$ & Corilagin $^{60}$ \\
\hline Sesquiterpene & Lindera strychnifolia & Roots & $\mathrm{CCl}_{4}$ & Lindstrem ${ }^{61}$ \\
\hline Caffeic acid & Salvia miltorhiza & Roots & D-galactosamine & Lithospermate B \\
\hline Furanone & Anoectochilus & Whole plant & $\mathrm{CCl}_{4}$ & Kinsenoside $^{62}$ \\
\hline Pterocarpane & Erycibe expansa & Stems & D-galactosamine & Erycibenin A \\
\hline Allyl thiosulfinates & Allium sativum & Bulbs & Isoniazid & Allicin ${ }^{63}$ \\
\hline Biflavonoid & Garcinia kola & Seeds & Paracetamol & Kolaviron ${ }^{64}$ \\
\hline Anthraquinone & Rubia cordifolia & Roots & $\mathrm{CCl}_{4}$ & Rubiadin \\
\hline
\end{tabular}

\section{Mechanism of hepatoprotective}

The hepatoprotective herbal drugs act through various mechanisms to protect against various deleterious effects. By involving through one or more mechanisms, they act on the hepatocyte liver directly or indirectly and help in proper functioning the mechanism involved elevated antioxidant level/minimise generation of free radicals by Reactive Oxygen Species (ROS) as well as reactive nitrogen species (RNS), downward regulation of cytochrome 450, immuno modulative and phagocytic, preventing lipid peroxidation and enhance the level of natural antioxidant endowed body.

Source and control of ROS and RNS level: The production of oxygen based radicals is the Bane to all aerobic species. ROS and RNS generated during cellular redox process by endogenous or exogenous sources. Endogenous system included mitochondrial electron transport of aerobic respiration or by oxido reductase enzymes and metal catalyzed oxidation immune cell activation, inflammation, energy production, mental stress, excessive exercise, ischemia, infection, by vascular endothelium to neutralise nitric oxide, ${ }^{65,66}$ regulate cell growth and differentiation, the respiratory burst, cancer, aging while exogenous result from air and water pollution, cigarette smoke, alcohol, heavy or transition metals ( $\mathrm{Cd}, \mathrm{Hg}, \mathrm{Pb}, \mathrm{Fe}, \mathrm{As})$, certain drugs (cyclosporine, tacrolimus, gentamycin, bleomycin), industrial solvents. Both system works as a second messenger. Nitric oxide ( $\mathrm{NO}$ ) has been shown to serve as decreasing blood pressure ${ }^{67}$ by vasodilation and neurotransmission through activation of soluble guanylated cyclase while Hydrogen peroxide is normally unreactive with thiols in the absence of catalyzing agents (e.g. enzymes, multivalent metals etc.), it does react with thiolate anion (S-), to form sulfenic acid, which in turn ionizes to form sulfenate (SO-). This intermediate can be reversed by the action of glutathione ${ }^{68}$

\section{$2 \mathrm{GSH}+\mathrm{H}_{2} \mathrm{O}_{2} \longrightarrow \mathrm{GSSG}+2 \mathrm{H}_{2} \mathrm{O}$}

Cellular membranes (because of their high lipid contents) are a common target for free radicals where a free radical will capture a hydrogen moiety from an unsaturated carbon to form water. This leaves an unpaired electron on the fatty acid that is then capable of capturing oxygen, forming a peroxy radical. Lipid peroxides are unstable and decompose to form a complex series of compounds, which include reactive carbonyl compounds, such as malondialdehyde (MDA) which can react with deoxy adenosine and deoxy guanosine in DNA to form DNA adducts, primarily pyrimidol. .9,70 $^{69}$

All free radical have very short half-life so evaluation of such thing is difficult therefore "trap" them by spin traps like alpha phenyl t-butyl nitrone (PBN) and cyclic nitrone spin traps. The molecules which antagonise the effect of free radicals called antioxidant, act by accepting or donating an electron to eliminate the unpaired condition at very low dose and final product may be water and oxygen (Figure 1). Nature has endowed us with protective antioxidant mechanisms which divided on their work like the primary defence system includes superoxide dismutase (SOD), glutathione peroxidase, catalase and thioredoxin reductase. Secondary defence's combat processes elicited by free-radicals. Main compounds belonging to the secondary defence system are ascorbic acid (vitamin $\mathrm{C}$ ), vitamin $\mathrm{E}$ (tocopherol and tocotrienols), glutathione (GSH), beta-carotene, lectoferrin or other metal containing proteins, vitamin $\mathrm{A}, \mathrm{NADPH}$ and urate $\mathrm{e}^{71-75}$ which came from diet or not.

Melatonin (N-acetyl-5-metyoxytryptamine) is also a powerful endogenous antioxidant, have significance roles in regulation of circadian rhythms, sleep, immune system activity and elimination of oxygen free radicals ${ }^{76,77}$ and worked through $G$ protein dependent 
receptors which lead to the induction of anti oxidant enzyme synthesis. ${ }^{78}$ In this way, melatonin neutralizes the effects of both oxygen and nitrogen-based reactive molecules. ${ }^{79}$ Melatonin induces the activity of glutamyl cysteine synthetase, there by stimulating the production of another intracellular antioxidant, glutathione. ${ }^{80}$

Inhibition of cytochrome P450: Cytochrome P450, a super family of heme-proteins metabolizes and activates many toxicologically important substrates, including ethanol, carbon tetrachloride, acetaminophen, and $\mathrm{N}$-nitroso dimethyl amine, to more toxic products $^{81-84}$ and metabolic clearance of numerous xenobiotics in the liver. They also play a critical role in the production of cholesterol, steroids, prostacyclins and thromboxane $\mathrm{A}_{2}$. There are more than 50 CYP450 enzymes identified in humans, metabolize $>90 \%$ of the clinically most important drugs. ${ }^{85,86}$ For example, the CYP3A enzymes metabolize over $40 \%$ of the drugs currently approved by the United
States Food and Drug Administration. Impairment of cytochrome P450 activity, which may be either genetic or environmental (inducer or inhibitor), may lead to toxicity caused by the parent compound itself. Various enzyme affected CYP450 family by up and down regulation such as- Barbiturates and chemicals that induce $\mathrm{CYP} 2 \mathrm{~B}$ initially interact with the constitutive androstane receptor (CAR) that translocate to the nucleus and dimerizes with the retinoid-X-receptor (RXR) and glutathione S-transferase A1/A2 (rGSTA1/A2). The dimer then binds to specific response elements, resulting in transcriptional activation of genes regulating P450 expression. ${ }^{87}$ Other hand Peroxisome proliferator-activated receptors (PPAR) are members of the steroid hormone receptor super family ${ }^{88}$ anszxcv1, and PPAR- $\alpha$ is associated with pleotropic responses induce PPAR activity, resulting in liver enlargement by stimulating the proliferation of hepatocyte peroxisomes and inducing the fatty acid oxidation enzyme CYP4A ${ }^{89}$

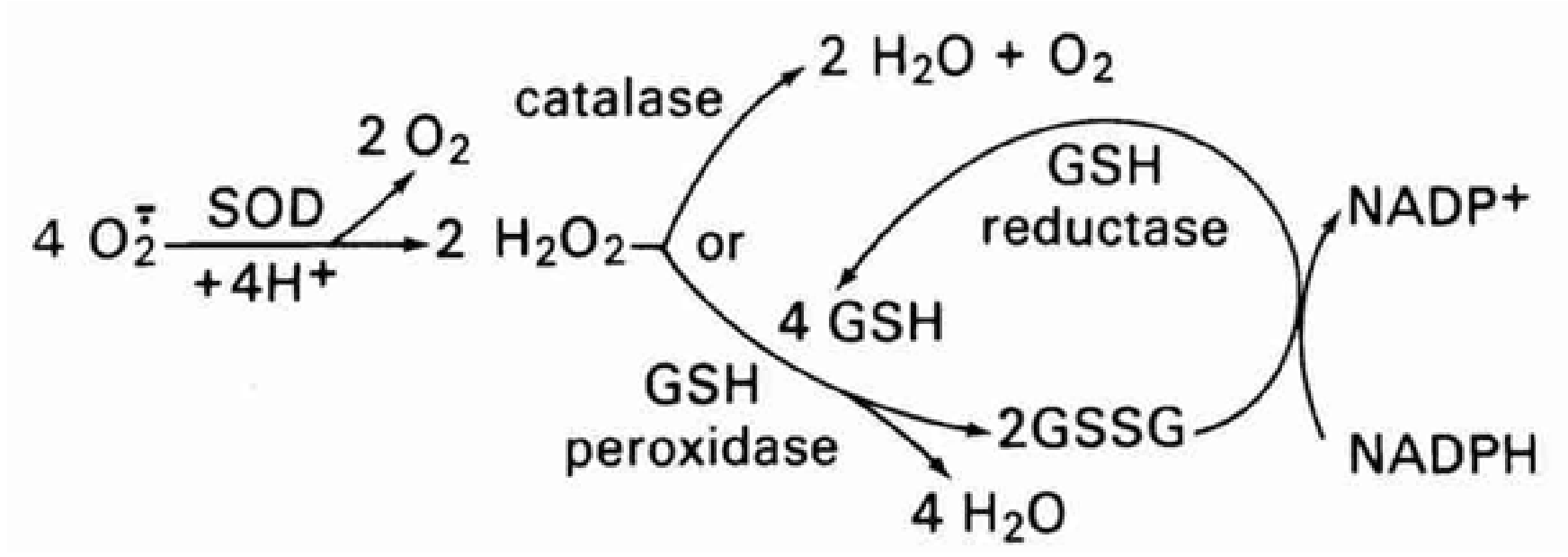

Figure I Scavenging activity of antioxidant molecules.

Inhibition of mitochondrial fatty acid $\beta$-oxidation: Recent studies show that tamoxifen, amlodipine and Valproicacid (VPA, or dipropylacetic acid) is an analogue of medium chain fatty acid which freely enters the mitochondrion and generates a coenzyme A ester (VPA-CoA) $)^{90,91}$ within the mitochondrial matrix. This VPACoA derivative can inhibit carnitine palmitoyltransferase-1 (CPT 1 ), an enzyme catalysing the rate limiting step of the mitochondrial entry and b-oxidation of long-chain fatty acids. ${ }^{92}$ Furthermore, the generation of the VPA-CoA ester reduces mitochondrial levels of $\mathrm{CoA}$, which is a cofactor mandatory for fatty acid oxidation (FAO). A second mechanism which could play a major role in VPA-induced inhibition of FAO is the cytochrome P450 (CYP)-mediated generation of D4-VPA. ${ }^{93,94}$ Indeed this metabolite also enters the mitochondrion to generate D2, 4-VPA-CoA, a reactive metabolite able to covalently bind to (and thus inactivate) FAO enzymes but above hypothesises are controversy.

Regulation of Interleukin 6 pathway: IL-6, pro-mitogenic and anti-apoptotic in nature for hepatocytes having both to delay and accelerate liver regeneration by down regulate Jak/STAT activation, e.g., transforming growth factor, granulocyte/macrophage colonystimulating factor (GM-CSF), and angiotensin II. ${ }^{95-97}$ When IL-6 binds to its soluble receptor, sIL-6r, which binds to the gp130 receptor, resulting in the activation of Janus Kinase (JAK). This leads to activation of the MAPK pathway and activation of Stat3 by tyrosine
(Y) phosphorylation. Homo dimerized Stat $3^{98}$ is able to translocate into the nucleus and activate gene transcription. In the liver, this process promotes liver regeneration, ${ }^{99}$ the acute-phase response and hepato protection against Fas and toxic damage. ${ }^{100-102,97}$

\section{Conclusion}

Several medicinal plants are now prevalent for the treatment of various liver diseases. Most of them are potential heptogenic/ heptoprotective against hepatototoxicity. They are considering as high safety margin, efficacy and cost effectiveness. Although different herbal drugs are used from long times ago but no precise their mechanism of action. While Considering the enormous biodiversity resources of India and coordinated research involving biomedical scientists, nutritionist, scholars working the field of pharmacology, therapeutics.

Pharmacognosy and other health professionals provided a big chance to develop evidence based alternative medicine to cure different kinds of liver diseases, included various pathways and molecules with their action. Research on free radicals and antioxidants involving these is one such effort in the right direction. This may be beneficial in the era of hepatoprotective.

\section{Acknowledgements}

None. 


\section{Conflict of interest}

The author declares no conflict of interest.

\section{References}

1. Sharma B, Sharma UK. Hepatoprotective activity of some indigenous plants. Int J Pharm Tech Res. 2010;2:568-572.

2. Meganathan M, Madhana Gopal K, Sasikala P, et al. Evaluation of antioxidant effect of Omega 3-fatty acid against paracetamol induced liver injury in albino rats. Global J Pharmacol. 2011;5(1):50-53.

3. Mossa JS, Tariq M, Mohsin A. Am J Chin Med. 1991;19:223.

4. Mascolo N, Sharma R, Jain SC, et al. J Ethnopharmacol. 1998;22:211.

5. Evans WC. An overview of drugs with antihepatoxic and oral hypoglyglycaemic activities. In: Evans WC, editor. Trease and Evans pharmacognosy. Scotland; 2002. p. 414-420.

6. Bharavi K, Gopala Reddy A, Rao GS, et al. Reversal of cadmium induced oxidative stress and its bioaccumulation by culinary herbs Murraya koenigii and Allium sativum. Research Journal of Pharmacology. 2010;4(3):60-65.

7. Habeebu SS, Liu J, Klaassen CD. Cadmium induced apoptosis in mouse liver. Toxicol Appl Pharmacol. 1998;149(2):203-209.

8. Russmann S, Gerd A, Grattagliano. Current Concepts of Mechanisms in Drug-Induced Hepatotoxicity. Current Medical Chemistry. 2009;16(23):3041-3053.

9. Temple R. Hepatotoxicity through the Years:Impact on the FDA. Food \& Drug Administration. 2001.

10. Trease GE, Evans WC. Pharmacognosy. London: Balliere Tindall Press; 1983. p. 56-57.

11. Sies H. Biochemistry of oxidative stress. Angewandte chemieinternational ed; 1986. 25:1058-1071.

12. Fernandez V, Videla LA. Biochemical aspects of cellular antioxidant systems. Biological Research. 1996;29(2):177-182.

13. Droge W. Free radicals in the physiological control of cell function. Physiological Reviews. 2002;82(1):47-95.

14. Oliva L, Beauge F, Choquart D, et al. Ursodeoxycholic acid alleviates alcoholic fatty liver damage in rats. Alcohol Clin Exp Res. 1998;22(7):1538-1543.

15. El-Sherbiny G, Taye A, Abdel-Raheem I. Role of urso deoxycholic acid in prevention of hepatotoxicity caused by amoxicillin-clavulanic acid in rats. Annals of Hepatology. 2009;8(2):134-140.

16. Lukivskaya O, Maskevich A, Buko V. Effect of ursodeoxycholic acid on prostaglandin metabolism and microsomal membranes in alcoholic fatty liver. Alcohol. 2001;25(2):99-105.

17. Kotb MA. Molecular mechanisms of ursodeoxycholic acid toxicity \& side effects: ursodeoxycholic acid freezes regeneration \& induces hibernation mode. International Journal of Molecular Sciences. 2012;13(7):8882-8914.

18. Buko V, Sadovnichy V. Cytochrome $\mathrm{P}-450$ and free radical gene-ration in rat liver microsomes under the influence of prostaglandin E1. Biochem Mol Biol Inter. 1996;39(6):1177-1184.

19. Buko V, Artsukevich A, Maltsev A, et al. Effect of polyunsaturated phosphatidylcholine on lipid structure and cAMP-dependent signal transduction in the liver of rats chronically intoxicated with ethanol. Exp Toxic Pathol. 1994;46(4-5):375-382.
20. Rathee JS, Patro BS, Mula S, et al. Antioxidant activity of Piper betel leaf extract and its constituents. Journal of Agricultural and Food Chemistry. 2006;54(24):9046-9054.

21. Handa SS, Sharma A, Chakraborti KK. Natural products and plants as liver protecting drugs. Fitoterapia. 1986;57:307-351.

22. Luper S. A review of plants used in the treatment of liver disease: part 1. Altern Med Rev. 1998;3(6):410-421.

23. Seef LB, Lindsay KL, Bacon B, et al. Complementary and alternative medicine in chronic liver disease. Hepatology. 2002;34(3):595-603.

24. Thyagarajan S, Jayaram S, Gopalakrishnan V, et al. Herbal medicines for liver diseases in India. J Gastroenterol Hepatol. 2002;17 Suppl 3:S370-S376.

25. Latha PG, Suja SR, Shyamal S, et al. Some hepatoprotective garden plants. Natural Product Radiance. 2005;4(4):278-279.

26. Prajapati ND, Purohit SS, Sharma AK, et al. A Handbook of medicinal plants. India: Agrobios; 2003.

27. Gupta VK, Sharma SK. Plants as natural antioxidents. Nat Prod Rad. 2006;5(4):326-334.

28. Kaur C, Kapoor HC. Antioxidents activity and total phenolic content of some Asian vegetables. Int J Food Sci Tech. 2002;37:153-161.

29. Ray G, Hussan SA. Oxidant, Antioxidant and carcinogenesis. Indian J Exp Biol. 2002;40(11):1213-1232.

30. Das J, Ghosh J, Roy A, et al. Mangiferin exerts hepatoprotective activity against D-galactosamine induced acute toxicity and oxidative/

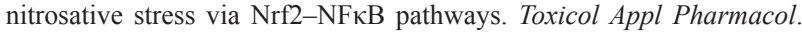
2012;260(1):45-47.

31. Senthil kumar R, Chandran R, Parimelazhagan P. Hepatoprotective effect of Rhodiola imbricata rhizome against paracetamol-induced liver toxicity in rats. Saudi Journal of Biological Sciences. 2014;21(5):409416.

32. Basu K, Dasgupta B, Bhattacharya SK, et al. Chemistry and pharmacology of apocynin, isolated from Picrorrhiza kurroa Royle ex Benth. Current Science. 1971;40(22):603-604.

33. Jain M, Kapadia R, Jadeja RN, et al. Hepatoprotective potential of Tecomella undulata stem bark is partially due to the presence of betulinic acid. Journal of Ethnopharmacology. 2012;143(1):194-200.

34. Imanshahidi M, Hosseinzadeh H. Pharmacological and therapeutic effects of Berberis vulgaris and its active constituent, berberine. Phytother Res. 2008;22(8):999-1012.

35. Rathi A, Srivastava AK, Shirwaikar A, et al. Hepatoprotective potential of Fumaria indica Pugsley whole plant extracts fractions and an isolated alkaloid protopine. Phytomedicine. 2008;15(6-7):470-477.

36. Lanhers MC, Joyeux J, Souliman R, et al. Hepatoprotective and AntiInflammatory Effects of a Traditional Medicinal Plant of Chile, Peumus boldus. Planta Medica. 1991;57(2):110-115.

37. Chandan BK, Sharma AK, Anand KK. Boerhaavia diffusa: A study of its hepatoprotective activity. Journal of Ethnopharmacology. 1991;31(3):299-307.

38. Hase K, Li J, Basnet P, et al. Hepatoprotective principles of Swertia japonica Makino on D-galactosamine/lipo polysaccharide-induced liver injury in mice. Chemical \& pharmaceutical bulletin. 1997;45(11):18231827.

39. Hyun C, Jun JY, Song EK, et al. Bakuchiol: A hepatoprotective compound of Psoralea corylifolia on tacrine-induced cytotoxicity in Hep G2 cells. Planta Medica. 2001;67(8):750-751. 
40. Chander R, Srivastava V, Tandon JS, et al. Antihepatotoxic activity of diterpenes of Andrographis paniculata (Kalmegh) against Plasmodium berghei induced hepatic damage in Mastomys natalensis. International Journal of Pharmacognosy. 1995;33(2):135-138.

41. Park EJ, Zhao YZ, Young HK, et al. Acanthoic acid from Acanthopanax koreanum protects against liver injury induced by tert-butyl hydroperoxide or carbon tetrachloride in vitro and in vivo. Planta Medica. 2004;70(4):321-327.

42. Yamamura Y, Kotaki H, Tanaka N, et al. The pharmacokinetics of glycyrrhizin and its restorative effect on hepatic function in patients with chronic hepatitis and in chronically carbon-tetrachloride-intoxicated rats. Biopharmaceutics \& Drug Disposition. 1997;18(8):717-772.

43. Oliveira FA, Chaves MH, Almeida FR, et al. Protective effect of alphaand beta-amyrin, a triterpene mixture from Protium heptaphyllum (Aubl.) March. Trunk wood resin, against acetaminophen-induced liver injury in mice. Journal of Ethnopharmacology. 2005;98(1-2):103-108.

44. Hikino H, Kiso Y, Amagaya S. Antihepatotoxic actions of papyriogenins and papyriosides, triterpenoids of Tetrapanax papyriferum leaves. Journal of Ethnopharmacology. 1984;12(2):231-235.

45. Kang SY, Sung SH, Park JH, et al. Hepatoprotective activity of scopoletin, a constituent of Solanum lyratum. Archives of Pharmacal Research. 1998;21(6):718-722.

46. GilaniuI AH, Janbaz KH, Shah BH. Esculetin prevents liver damage induced by Paracetamol and $\mathrm{CCl}_{4}$. Pharmacological Research. 1998;37(1):31-35.

47. Murali A, Purnima A, Madhavan V. Antioxidant and hepatoprotective effects of the roots of Hemidesmus indicus. Asian Journal of Traditional Medicines. 2013:8(1).

48. Shanthasheela R, Chitra R, Vijayachitra M. Evaluation of Hepatoprotective Activity of combination of Anethum graveolens and Agave Americana on $\mathrm{CCL}_{4}$ Intoxicated Rats. Indian Drugs-Bombay. 2007;44(12):950-952.

49. Baligar NS, Aladakatti RH, Ahmed M, et al. Hepatoprotective activity of the neem-based constituent azadirachtin-A in carbon tetrachloride intoxicated Wistar rats. Can J Physio Pharmacol. 2014;92(4):267-277.

50. Adzet T, Camarasa J, Laquna JC. Hepatoprotective activity of polyphenolic compounds from Cynara scolymus against $\mathrm{CCl}_{4}$ toxicity in isolated rat hepatocytes. J Nat Prod. 1987;50(4):612-617.

51. Hikino H, Kiso Y, Wagner, et al. Antihepatotoxic actions of flavonolignans from Silybum marianum fruits. Planta Medica. 1984;50(3):248-250.

52. Hikino H, Sugai T, Kanno C, et al. Liver protective Principle of Thujopsis dolabrata leaves. Planta Medica. 1979;36(2):156-163.

53. Krithika R, Verma R. Ameliorative effects of phyllanthin on carbon tetrachloride-induced hepatic oxidative damage in mice. Asian Pacific Journal of Tropical Disease. 2014;4(1):S64-S70.

54. Huang ZS, Wang ZW, Liu MP, et al. Protective effects of polydatin against $\mathrm{CCl}_{4}$-induced injury to primarily cultured rat hepatocytes. World Journal of Gastroenterology. 1999;5(1):41-44.

55. Chen J, Zhang J, Zhuang Q, et al. Electrochemical study of bergenin on a poly(4-(2-pyridylazo)-resorcinol) modified glassy carbon electrode and its determination in tablets and urine. Talanta. 2007;72(5):18051810

56. Rios JL, Recio MC, Giner RM, et al. An update review of saffron and its active constituents. Phytotherapy research. 1996;10:189-193.

57. Anand KK, Singh B, Saxena AK, et al. 3, 4, 5-Trihydroxy benzoic acid (gallic acid), the hepatoprotective principle in the fruits of Terminalia belerica-bioassay guided activity. Pharmacological Research. 1997;36(4):315-321.
58. Rao KS, Mishra SH. Antihepatotoxic activity of monomethyl fumarate isolated from Fumaria indica. Journal of Ethnopharmacology. 1998;60(3):207-213.

59. Singh B, Saxena AK, Chandan BK, et al. Hepatoprotective activity of indigtone: A bioactivefraction from Indigofera tinctoria Linn. Phytotherapy Research. 2001;15(4):294-297.

60. Kinoshita S, Inoue Y, Nakama S, et al. Antioxidantand hepatoprotective actions of medicinal herb, Terminaliacatappa $L$. from Okinawa Island and its tannin corilagin. Phytomedicine. 2007;14:755-762.

61. Kouno I, Hirai A, Fukushige A, et al. New Eudesmane Sesquiterpenes from the Root of Lindera strychnifolia. J Nat Prod. 2001;64(3):286-288.

62. Wu JB, Chuang HR, Yang LC, et al. A Standardized aqueous extract of Anoectochilus formosanus ameliorated thioacetamide-induced liver fibrosis in mice:the role of Kupffer Cells. Biosci biotech biochem. 2010;74:781-787.

63. Nagui T, Magdy AA. Hepatoprotective Activity of Allicin Against Carbon Tetrachloride Induced Hepatic Injury in Rats. $J$ Bio Scie. 2006;6(3):457-468

64. Farombi EO. Mechanisms for the hepatoprotective action of kolaviron:studies on hepatic enzymes, microsomal lipids and lipid peroxidation in carbontetrachloride-treated rats. Pharmacolo Res. 2000;42(1):75-80.

65. Tsao PS, Heidary S, Wang A. Protein kinase C-epsilonmediates glucoseinduced superoxide production and $\mathrm{MCP}-1$ expression in endothelial cells. FASEB J. 1998;12:512.

66. Masters CJ. Cellular signalling:the role of the peroxisome. Cell Signal. 1996;8(3):197-208

67. Hou YC, Janczuk A, Wang PG. Current trends in the development of nitric oxide donors. Curr Pharm Des. 1999;5(6):417-471.

68. Forman HJ Torres M. Reactive Oxygen Species and Cell Signaling: respiratory Burst in Macrophage Signaling. Am J Respir Crit Care Med. 2002;166(12 pt 2):s4-s8.

69. Zhou X, Taghizadeh K, Dedon PC. Chemical and biological evidence for base propenalsas the major source of the endogenous M1dG adduct in cellular DNA. J Biol Chem. 2005;280:25377-25382.

70. Marnett LJ. Lipid peroxidation-DNA damage by malondialdehyde. Mutat Res. 1999;424(1-2):83-95.

71. Beaudeux JL, Gardes-Albert M, Delattre J, et al. Resistance of lipoprotein(a) to lipid peroxidation induced by oxygenated free radicals produced by gamma radiolysis: a compari- son with low-density lipoprotein. Biochem J. 1996;314:277-284.

72. SE Stait, Leake DS. The effects of ascorbate and dehydroascorbate on the oxidation of low-density lipo- protein. Biochem J. 1996;320(pt 2):37-81.

73. Hall L, Williams K, Perry AC, et al. The majority of human glutathione peroxidase type 5 (GPX5) transcripts are incorrectly spliced: implications for the role of GPX5 in the male reproductive tract. Biochem J. 1998;333(pt 1):5-9.

74. Patterson RA, Leake DS. Human serum, cysteine and histidine inhibit the oxidation of low density lipoprotein less at acidic pH. FEBS Lett. 1998;434(3):317-321.

75. Stahl W, Junghans A, de Boer B, et al. Carotenoid mixtures protect multila-mellar liposomes against oxidative damage: synergistic effects of lycopene and lutein. FEBS Lett. 1998;427(2):305-308.

76. Allegra M, Reiter RJ, Tan DX, et al. The chemistry of melatonin's interaction with reactive species. J Pineal Res. 2003;34(1):1-10. 
77. Tan DX, Manchester LC, Reiter RJ, et al. Melatonin directly scavenges hydrogen peroxide:a potentially new metabolic pathway of melatonin biotransformation. Free Radical Biology and Medicine. 2000;29:11771185 .

78. Abdel-Wahab MH, Abd-Allah AR. Possible protective effect of melatonin and/or desferrioxamine against streptozotocininduced hyperglycaemia in mice. Pharmacol Res. 2001;41(5):533-537.

79. Sudnikovich EJ, Maksimchik YZ, Zabrodskaya SV, et al. Melatonin attenuates metabolic disorders due to streptozotocin-induced diabetes in rats. European Journal of Pharmacology. 2007;569(3):180-187.

80. Winiarska K, Fraczyk T, Malinska D, et al. Melatonin attenuates diabetesinduced oxidative stress in rabbits. J Pineal Res. 2006;40(2):168-176.

81. Guengerich FP, Kim DH, Iwasaki M. Role of human cytochrome P450 IIE1 in the oxidation of many low molecular weight cancer suspects. Chem Res Toxicol. 1991;4(2):168-179.

82. Koop DR. Oxidative and reductive metabolism by cytochrome P4502E1 FASEB J. 1992;6(2):724-730.

83. Anzenbacher P, Anzenbacherová E. Cytochromes P450 and metabolism of xenobiotics. Cell Mol Life Sci. 2001;58(5-6):737-747.

84. Dahm LJ, Jones DP. Mechanisms of chemically induced liver disease. In: Zakin D, Boyer TD, editors. Hepatology: a textbook of liver disease. 3rd ed. 1996. pp. 875-890.

85. Wilkinson GR. Drug metabolism and variability among patients in drug response. N Engl J Med. 2005;352(21):2211-2221.

86. Slaughter RL, Edwards DJ. Recent advances: the cytochrome P450 enzymes. Ann Pharmacother. 1995;29(6):619-624.

87. Liang Q, He JS, Fulco AJ. The role of Barbie box sequences as cisacting elements involved in the barbiturate-mediated induction of cytochromes P450BM-1 and P450BM-3 in Bacillus megaterium. J Biol Chem. 1995;270(9):4438-4450.

88. Peters JM, Cattley RC, Gonzalez FJ. Role of PPAR alpha in the mechanism of action of the nongenotoxic carcinogen and peroxisome proliferator Wy-14,643. Carcinogenesis. 1997;18(11):2029-2033.

89. Aoyama T, Peters JM, Iritani N, et al. Altered constitutive expression of fatty acid-metabolizing enzymes in mice lacking the peroxisome proliferator-activated receptor alpha (PPAR alpha). J Biol Chem. 1998;273(10):5678-5684.

90. Rettenmeier AW, Prickett KS, Gordon WP, et al. Studies on the biotransformation in the perfused rat liver of 2-npropyl-pentenoic acid, a metabolite of the antiepileptic drug valproic acid. Evidence for the formation of chemically reactive intermediates. Drug Metab Dispos. 1985;13(1):81-96.
91. Silva MF, Ruiter JP, IJIst L, et al. Differential effect of valproate and its Delta2- and Delta4-unsaturated metabolites, on the beta-oxidation rate of long-chain and medium-chain fatty acids. Chem Biol Interact. 2001;137(3):203-212.

92. Fromenty B, Pessayre D. Inhibition of mitochondrial beta-oxidation as a mechanism of hepatotoxicity. Pharmacol Ther. 1995;67(1):101-154.

93. Baldwin GS, Murphy VJ, Yang Z, et al. Binding of non steroidal anti inflammatory drugs to the a-subunit of the tri functional protein of long chain fatty acid oxidation. J Pharmacol Exp Ther. 1998;286(2):1110 1114 .

94. Fromenty B, Freneaux E, Labbe G, et al. Tianeptine, a new tricyclic antidepressant metabolized by beta-oxidationof its heptanoic side chain, inhibits the mitochondrial oxidation of mediumand short chain fatty acids in mice. Biochem Pharmacol. 1989;38(21):3743-3751.

95. Sengupta TK, Schmitt EM, Ivashkiv LB. Inhibition of cytokines and Jak-STAT activation by distinct signaling pathways. Proc Natl Acad Sci USA. 1996;93(18):9499-9504.

96. Bhat GJ, Abraham ST, Baker KM. Angiotensin II interferes with interleukin-6-induced STAT3 signaling by a pathway involving mitogen-activated protein kinase kinase 1. J BiolChem. 1996;271(37):22447-22452.

97. Takeda K, Noguchi K, Shi W, et al. Targeted disruption of the mouse Stat3 gene leads to early embryonic lethality. Proc Natl Acad Sci USA. 1997;94(8):3801-3804.

98. Dittrich E, Renfrew-Haft C, Muys L, et al. A di-leucine motif and an upstream serine in the interleukin-6 (IL-6) signal transducergp130 mediate ligand-induced endocytosis and down-regulation of the IL-6 receptor. J Biol Chem. 1996;271(10):5487-5494.

99. Levy DE, Lee CK. What does Stat3 do? J Clin Invest. 2002;109(9):11431148.

100. Hirano T, Ishihara K, Hibi M. Roles of STAT3 in mediating the cell growth, differentiation and survival signals relayed through the IL-6 family of cytokine receptors. Oncogene. 2000;19(21):2548-2556.

101. Bowman T, Garcia R, Turkson J, et al. STATs in oncogenesis. Oncogene. 2000;19(21):2474-2488.

102. Li W, Liang X, Kellendonk C, et al. STAT3 contributes to the mitogenic response of hepatocytes during liver regeneration. J Biol Chem. 2002;277(32):28411-28417. 